\title{
Step-by-Step zum Online-Archiv und zur CME-Fortbildung
}

Die Mitglieder der Deutschen Gesellschaft für Allergologie und klinische Immunologie (DGAKI), die Mitglieder des Ärzteverbands Deutscher Allergologen (AeDA) sowie alle Abonnenten des Allergo Journal können online auf das Allergo-JournalArchiv, das bis 1997 zurückreicht, zugreifen. Beheimatet ist das Online-Archiv des Allergo Journal auf dem gerade frisch überarbeiteten Medizinportal www.springermedizin.de. Auf SpringerMedizin.de können Abonnenten und Gesellschaftsmitglieder zudem kostenlos mit den CME-Modulen aus dem Allergo Journal Punkte sammeln. Hier eine Anleitung, wie Sie sich das Online-Angebot freischalten können.

Rufen Sie die Website www.springermedizin.de in Ihrem Browser auf und loggen Sie sich mit Ihrem Springer- Medizin-Passwort ein. Sollten Sie noch kein SpringerMedizin-Passwort haben, klicken Sie ebenfalls zunächst auf "Login“ und dann auf den Link „Dann registrieren Sie sich jetzt kostenlos und unverbindlich!“. Folgen Sie nun den Anweisungen. Um Zugang zu erhalten, ist ein Berufsnachweis erforderlich.

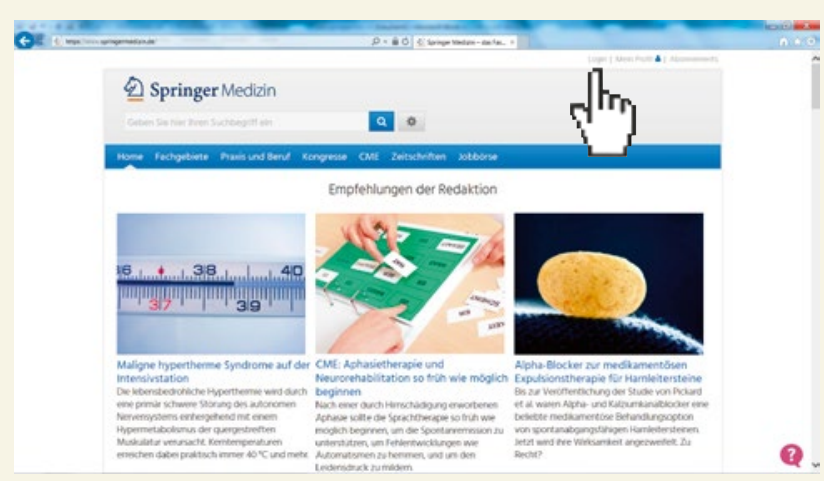

2

Nun gilt es, sich das Allergo Journal freischalten zu lassen. Klicken Sie dazu nach dem Login auf „Mein Profil“.

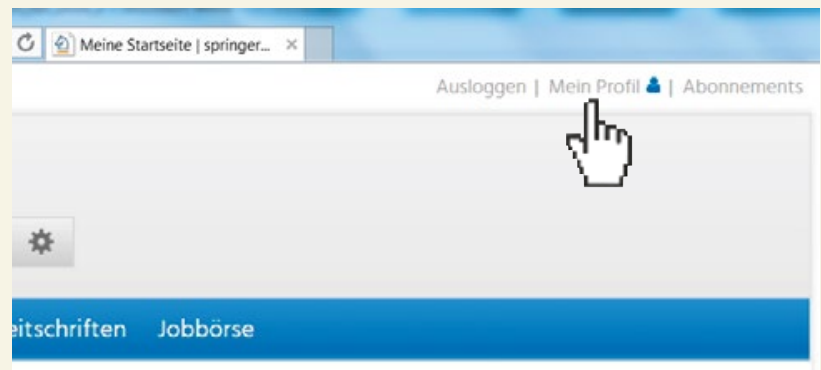

\section{Startseite}

en der Redaktion
Klicken Sie nun auf "Meine Abos", scrollen Sie etwas nach unten und klicken Sie dann auf "Abo hinzufügen". - Halten Sie für den nächsten Schritt Ihre Abonnentennummer parat. Diese finden Sie auf dem Adressaufkleber Ihrer Allergo-Journal-Printausgabe.
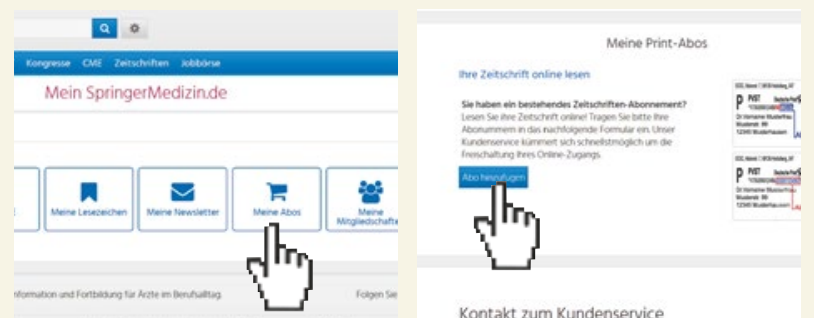

Kontakt zum Kundenservice

4.

Tragen Sie Ihre Abonnentennummer und die Lieferanschrift, die auf dem Etikett angegeben ist, in das - Formular ein und klicken Sie danach auf "senden".

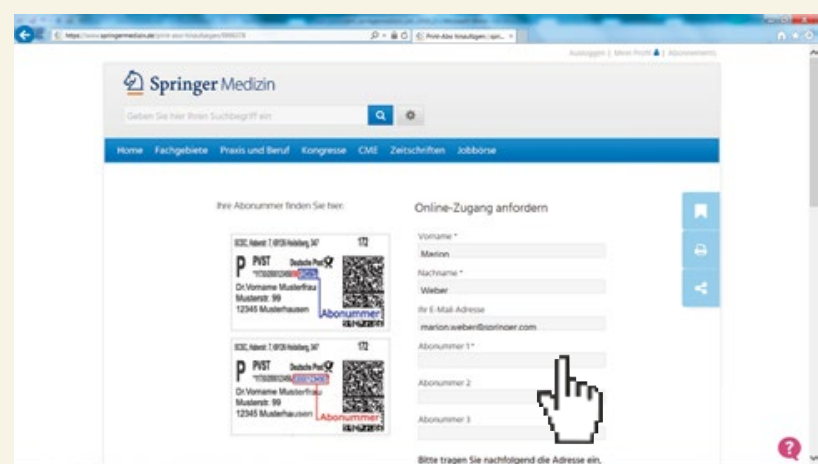

- Jetzt haben Sie Zugriff auf das Online-Archiv des Allergo Journal auf SpringerMedizin.de. Und nicht nur das: Sie - haben jetzt auch kostenlos Zugang zu den CMEzertifizierten Beiträgen aus dem Allergo Journal. Wählen Sie dazu mit dem Mauszeiger die Rubrik "CME" und suchen Sie sich - zum Beispiel über "Auswahl nach Zeitschriften" - das Allergo Journal aus. Viel Spaß beim Recherchieren, Fortbilden und Lesen.

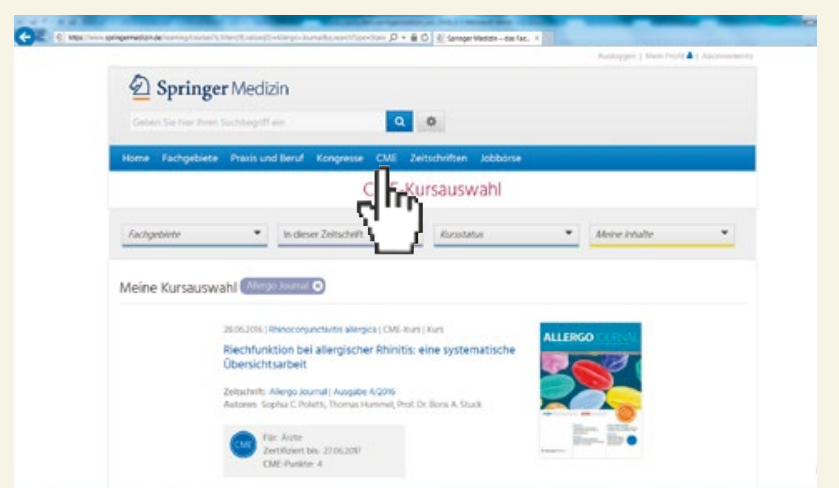

